\title{
MANAGEMENT OF VIRAL RETINITIS-ASSOCIATED RETINAL DETACHMENT IN AIDS
}

\author{
D. HANNOUCHE, J. F. KOROBELNIK, I. COCHEREAU and T. HOANG-XUAN \\ Paris, France
}

\begin{abstract}
SUMMARY
We retrospectively reviewed the results of surgery in 27 cases of retinal detachment related to viral necrotising retinitis in acquired immune deficiency syndrome (AIDS). Vitrectomy and silicone oil tamponade were performed in all cases. Scleral buckling was applied to 9 eyes. Silicone oil was left in the eye in all cases. Mean follow-up period was 13 weeks. Post-operative flattening of the retina at the posterior pole was achieved in $89 \%$ of the eyes. Anatomical results were not related to the' intraoperative use of an encircling procedure. Visual acuity improved by 2 Snellen lines or more in $40 \%$ of cases and $67 \%$ of the eyes retained a postoperative ambulatory vision. Phacosclerosis and optic atrophy developed in $29 \%$ and $22 \%$ of cases, respectively. Vitrectomy and silicone oil tamponade without scleral buckling are effective in the management of retinitis-associated retinal detachments. This procedure is short and can be performed under local anaesthesia.
\end{abstract}

Cytomegalovirus (CMV) and varicella zoster virus (VZV) retinitis are the two most common ocular manifestations in acquired immune deficiency syndrome (AIDS). Rhegmatogenous retinal detachment occurs in $17-34 \%{ }^{1,2}$ and $70 \%^{3}$ of the involved eyes, respectively. Its incidence is increasing owing to the extension of patients' life expectancy. Preservation of visual function in these eyes requires control of the retinitis using active antiviral medication and management of the related retinal detachment.

Extraocular explantation has failed to cure these rhegmatogenous retinal detachments, ${ }^{2,4,5}$ which are related to small, multiple breaks, often posteriorly located, at the margins of or over the inactive retinitis. Laser photocoagulation around the detached area does not prevent the progression of subretinal fluid. ${ }^{6}$ Recurrent detachments have been

From: Department of Ophthalmology, Bichat-Claude Bernard Hospital, Paris, France.

Correspondence to: Jean-François Korobelnik, Department of Ophthalmology, Bichat-Claude Bernard Hospital, 46, rue Henri Huchard, F-75877 Paris Cedex 18, France. reported after vitrectomy and gas tamponade., Good anatomical results have been achieved after scleral buckling, vitrectomy and silicone oil tamponade. . $^{7-13}$

We retrospectively reviewed 27 consecutive cases of viral retinitis-related retinal detachment in AIDS patients. Vitrectomy and silicone oil tamponade with or without scleral buckling were performed in all cases. We analysed the anatomical and functional results after both surgical procedures.

\section{PATIENTS AND METHODS}

Twenty-seven eyes of 26 consecutive patients were included in the study between September 1993 and September 1995. Clinical diagnosis of CMV or VZV retinitis was established in 24 eyes and 3 eyes, respectively. Antiviral therapy for both types of retinitis consisted of intravenous ganciclovir $(10 \mathrm{mg} /$ $\mathrm{kg}$ per day) or foscarnet $(180 \mathrm{mg} / \mathrm{kg}$ per day $)$ administered as an induction therapy when the retinitis was active, followed by a half-dose maintenance therapy when the lesions were healed. Intravitreous injections of $400 \mu \mathrm{g}$ of ganciclovir were performed in cases of systemic intolerance to intravenous medication. When necessary, they were continued post-operatively through a vitreous cavity filled with silicone oil.

Rhegmatogenous retinal detachments threatening or involving the macula were selected for surgery. Eyes presenting with preoperative optic atrophy or retinal necrosis involving the macula or the optic disc were excluded. Surgery was performed within the week following the diagnosis of retinal detachment. General anaesthesia was used for the first 21 procedures. The last 6 patients underwent surgery under local anaesthesia using a peribulbar injection of xylocaine $2 \%$, bupivacaine $0.5 \%$ and hyaluronidase.

A three-port pars plana vitrectomy with silicone oil tamponade was performed in 27 eyes. Two recurrent detachments after a previous extraocular procedure

Eye (1997) 11, 33-36 CC 1997 Royal College of Ophthalmologists 
(1 eye) or vitrectomy with gas tamponade (1 eye) were included. Of the 27 operated eyes, two groups were identified: a first group (group 1) of 9 eyes was administered an encircling scleral buckle $5 \mathrm{~mm}$ wide and a second group of 18 eyes (group 2) did not have any explant associated with the intraocular procedure. If scleral buckling was applied, an intraoperative anterior chamber puncture was performed to prevent an excessive increase in the intraocular pressure. Ganciclovir $(30 \mu \mathrm{g} / \mathrm{ml})$ was added to the balanced salt infusion solution in all cases. ${ }^{14}$ The vitrectomy was performed as completely as possible. The posterior hyaloid was removed if not already detached. Epiretinal membranes were isolated and peeled. The retinal reattachment procedure consisted of perfluorocarbon liquid (perfluorodecalin, DK-line, Opsia) instillation through the vitreous cavity in 15 eyes and direct fluid-silicone oil exchange in the 12 remaining eyes. Complete endodrainage of subretinal fluid was carried out in all cases through existing breaks, or posterior retinotomy. Complete filling of the vitreous cavity with silicone oil (1300 centistokes; Oxane, Opsia) was then achieved in all cases. Endophotocoagulation was applied to all visible retinal breaks, around drainage sites and at the margins of the retinitis area. Post-operative examination was performed at day 1 , day 10, and twice a month thereafter. This included measurement of visual acuity, and the evaluation of retinal reattachment and retinitis activity. Silicone oil was left in the eye in all cases.

\section{RESULTS}

Twenty-two men and four women were included in the study. The mean age was 38 years (range 26-54 years). The CD4 lymphocyte count was less than $50 \mathrm{~mm}^{3}$ in all cases. The mean follow-up period was 13 weeks (range 1-40 weeks).

Retinal detachment occurred after a mean period of 10 months in CMV retinitis and 3 weeks in VZV retinitis. It was bilateral in 19 cases $(73 \%)$. At the time of surgery, the retinitis was inactive in 16 eyes (59\%). Intravenous ganciclovir and foscarnet had been administered to 16 patients $(61 \%)$ and 10 patients $(39 \%)$, respectively. Intravitreous injections of ganciclovir had been performed preoperatively in 11 eyes (40\%) and were continued post-operatively through a vitreous cavity filled with silicone oil in 5 eyes. No adverse events were reported in these latter cases.

The retinal detachment was bilateral in 7 cases $(27 \%)$. It involved the macula in 22 eyes $(82 \%)$. Preoperative proliferative vitreoretinopathy (PVR) of grade $\mathrm{CP} 1$ or more was reported in 2 eyes $(7 \%)$, 1 of which was a recurrent detachment. Multiple atrophic microholes were identified at the margins of the inactive retinitis areas in 23 eyes (85\%). Preoperative posterior vitreous detachment was found in 12 eyes $(45 \%)$ and successful intraoperative

Table I. Results of surgery in viral retinitis-associated retinal detachment in AIDS

\begin{tabular}{|c|c|c|c|c|c|c|c|}
\hline \multirow{2}{*}{$\begin{array}{l}\text { Patient no./ } \\
\text { age/sex }\end{array}$} & \multirow{2}{*}{$\begin{array}{l}\text { Follow-up } \\
\text { (weeks) }\end{array}$} & \multirow[b]{2}{*}{ Retinitis } & \multicolumn{2}{|c|}{ Surgery } & \multirow{2}{*}{$\begin{array}{l}\text { Total retinal } \\
\text { reattachment }\end{array}$} & \multirow{2}{*}{$\begin{array}{c}\text { Pre-operative } \\
\text { VA }\end{array}$} & \multirow{2}{*}{$\begin{array}{c}\text { Post-operative } \\
\text { VA }\end{array}$} \\
\hline & & & Vit + SOT & SB & & & \\
\hline $1 / 44 / \mathrm{M}$ & 39 & VZV & + & - & + & $20 / 100$ & $1 / 100$ \\
\hline 2/44/M & 35 & VZZV & + & - & + & LP & LP \\
\hline 3/39/M & 16 & CMV & + & + & + & LP & 20/100 \\
\hline 4/42/M & 3 & CMV & + & - & + & $1 / 200$ & $1 / 200$ \\
\hline $5 / 47 / \mathrm{M}$ & 40 & CMV & + & - & + & $1 / 200$ & $20 / 60$ \\
\hline 6/43/M & 21 & CMV & + & - & + & $20 / 100$ & $1 / 100$ \\
\hline 7/26/M & 8 & CMV & + & - & + & $1 / 200$ & LP \\
\hline $8 / 54 / \mathrm{M}$ & 8 & CMV & + & - & + & $20 / 200$ & 20/100 \\
\hline 9/35/M & 3 & CMV & + & - & - (inf RD) & $20 / 100$ & $20 / 60$ \\
\hline $10 / 35 / F$ & 2 & CMV & + & - & $-(\inf R D)$ & $1 / 100$ & $20 / 60$ \\
\hline $11 / 39 / \mathrm{F}$ & 1 & CMV & + & - & + & $20 / 40$ & $1 / 100$ \\
\hline $12 / 37 / \mathrm{M}$ & 4 & CMV & + & - & + & $1 / 100$ & $20 / 100$ \\
\hline $13 / 38 / \mathrm{F}$ & 29 & CMV & + & + & + & $1 / 100$ & 20/100 \\
\hline 14/47/M & 26 & CMV & + & + & + & $1 / 100$ & $20 / 40$ \\
\hline $15 / 45 / \mathrm{M}$ & 26 & CMV & + & + & + & $1 / 100$ & $20 / 100$ \\
\hline 16/40/M & 13 & CMV & + & + & + & $20 / 200$ & 20/100 \\
\hline $17 / 42 / \mathrm{F}$ & 13 & CMV & + & + & + & $1 / 100$ & $20 / 50$ \\
\hline $18 / 46 / \mathrm{M}$ & 2 & CMV & + & + & + & $1 / 100$ & $20 / 50$ \\
\hline $19 / 34 / F$ & 4 & CMV & + & + & + & $1 / 100$ & $20 / 200$ \\
\hline 20/38/M & 13 & CMV & + & - & - (inf RD) & 20/100 & $20 / 60$ \\
\hline 21/49/M & 1 & VZV & + & + & + & $1 / 100$ & LP \\
\hline 22/49/M & 26 & CMV & + & + & + & $1 / 100$ & $1 / 200$ \\
\hline 23/31/M & 1 & CMV & + & + & + & LP & $1 / 100$ \\
\hline 24/35/M & 4 & CMV & + & + & + & LP & $1 / 100$ \\
\hline $25 / 31 / \mathrm{M}$ & 1 & CMV & + & + & + & $20 / 100$ & $20 / 200$ \\
\hline 26/37/M & 13 & CMV & + & + & + & $1 / 100$ & $1 / 100$ \\
\hline $27 / 33 / \mathrm{M}$ & 17 & CMV & + & + & + & LP & $1 / 100$ \\
\hline
\end{tabular}

VZV, varicella zoster virus; CMV, cytomegalovirus; Vit, vitrectomy; SOT, silicone oil tamponade; SB, scleral buckling; inf RD, inferior retinal detachment; VA, visual acuity; LP, light perception. 
removal of the attached posterior hyaloid was performed in the remaining 15 eyes $(55 \%)$. No intraoperative arterial spasm was reported after perfluorocarbon liquid or silicone oil injection.

Results of surgery are summarised in Table I. Postoperative flattening of the retina was achieved in all eyes. A recurrent detachment associated with PVR was reported in 1 eye $(11 \%)$ of group 1 with scleral buckling, after a 5 month period. No reintervention was performed. Shallow inferiorly located retinal detachments developed in 2 eyes of $18(11 \%)$ in group 2 without scleral buckling. No reintervention was performed since the retinal detachment did not extend beyond the inferior temporal vascular arcades during the follow-up period.

The mean best corrected preoperative visual acuity was 20/200 (range: light perception to 20/40). The mean best post-operative visual acuity was 20/120 (range: light perception to 20/40) after correction of silicone-induced hyperopia. Visual acuity improved by 2 Snellen lines or more in 11 eyes $(41 \%)$. Eighteen eyes $(67 \%)$ retained a postoperative ambulatory vision $(>5 / 200)$. Eyes affected with CMV retinitis achieved a mean post-operative visual acuity of 20/100. Eyes affected with VZV retinitis achieved a mean post-operative visual acuity of 20/4000. The mean post-operative best corrected visual acuity was similar in eyes with or without preoperative macular detachment. The exclusion of scleral buckling did not influence retinal reattachment or visual outcome.

Phacosclerosis developed in 8 eyes $(29 \%), 2-8$ months (mean 5 months) after surgery. Five eyes required cataract extraction during the first postoperative year. Phacoemulsification with capsular bag implantation was successfully performed in these 5 cases. No silicone oil loss was reported after cataract surgery.

Progressive visual impairment related to optic atrophy occurred in 6 eyes (22\%), 1-4 months after surgery. Two of these eyes had undergone scleral buckling.

Fourteen patients (54\%) died during the follow-up period. Their mean survival time was 5 months.

\section{DISCUSSION}

Rhegmatogenous retinal detachment associated with viral retinitis is a major cause of severe visual impairment in AIDS patients. AIDS patients are at high risk of blindness since the contralateral eye may experience retinal necrosis of the posterior pole, optic atrophy or rhegmatogenous retinal detachment in $46-67 \%$ of cases. ${ }^{15,16}$ The incidence of retinal detachment in viral retinitis is related to the involvement of pre-equatorial retina ${ }^{2}$ and to the extent ${ }^{2,16}$ and duration of retinitis. It occurs over active $^{15-17}$ or healed ${ }^{4}$ retinitis. Multiple posterior microholes, usually found at the junction between retinitis and uninvolved retina, require permanent internal tamponade which is best achieved by silicone oil tamponade.

We report here the results of vitrectomy and silicone oil tamponade, with or without scleral buckling, in eyes.presenting with rhegmatogenous retinal detachment involving the posterior pole.

At the time of the last visit, the rate of macular reattachment reached $89 \%$ in eyes with scleral buckling and $89 \%$ in eyes without scleral buckling. These results are consistent with previous studies $4,18,19$ which reported a final macular reattachment rate of $82-84 \%$ after procedures excluding scleral buckling.

The systematic use of an encircling procedure in these eyes has been advocated to obtain a higher rate of total retinal reattachment, ${ }^{11,12}$ reduction of silicone-induced hyperopia ${ }^{18}$ and release of the vitreous base. Incomplete tamponade of inferior holes by silicone oil has justified the use of scleral buckling although the explant can not tamponade all the inferior necrotic area. ${ }^{10}$

We believe that the exclusion of scleral buckling from the procedure can be considered in these eyes because of the low rate of associated PVR. As the posterior hyaloid has been removed, post-operative PVR rarely develops. ${ }^{2,6,10}$ This could be related to the alteration of immunity in AIDS patients. Scleral buckling can induce intraoperative variations in intraocular pressure with potential alteration of optic disc perfusion. Another advantage of excluding scleral buckling is the reduction of the intraoperative time. Shorter procedures allow the use of local anaesthesia without discomfort for the patients. This argument has to be considered in patients who are in poor general condition.

Inferior limited retinal detachments sometimes develop after vitrectomy and silicone oil tamponade without scleral buckling. They do not interfere with visual recovery since they involve necrotic retina and usually do not reach the posterior pole. In our series, these eyes did not require reintervention.

Despite poor visual outcome, $67 \%$ of the eyes retained a post-operative ambulatory vision $(>5 / 200)$. An improvement of visual acuity of 2 Snellen lines or more was observed in 11 eyes $(41 \%)$. Visual prognosis was unrelated to the intraoperative use of an encircling procedure. Although a small number of VZV cases was included, functional results seemed to be poorer in VZV retinitis than in CMV retinitis. VZV retinitis involved the macula more frequently and was commonly associated with optic atrophy.

Five eyes with macula-on retinal detachments were included in our series. These patients experienced immediate post-operative deterioration of visual acuity due to silicone-oil-induced hyperopia. 
Therefore, we believe that surgery can be delayed until macular detachment occurs. If surgery is performed within a few days of macular detachment, vision usually recovers.

Optic atrophy was responsible for progressive secondary visual impairment in $22 \%$ of the eyes in the 4 post-operative months. This complication may be attributed more to the extent of the retinitis itself than to the surgical procedure.

Post-operative reactivation of the retinitis with macular involvement remains a common cause of secondary visual $\operatorname{loss}^{7}$ and requires the continuation of antiviral therapy post-operatively. We have administered intravitreous injections of ganciclovir through silicone oil as a maintenance therapy in 5 eyes of 5 patients who could not benefit from systemic medication. No relapse of retinitis was observed, and no adverse effect was reported. The efficacy of this procedure can not be assessed because of the small number of cases included. The diffusion of ganciclovir into the fluid surrounding the silicone oil bubble may, however, prevent a relapse of the retinitis.

This study confirms the efficacy of vitrectomy, posterior hyaloid peeling and silicone oil tamponade without scleral buckling in the management of viral retinitis-associated retinal detachments in AIDS. Our approach is to select for surgery eyes with recent macular detachment, with no preoperative optic atrophy or posterior pole necrosis. Surgery is recommended in these cases owing to the expected visual improvement. Since a short procedure excluding scleral buckling is performed, local anaesthesia should be preferred in these patients in poor general condition. Filling of the vitreous cavity with silicone oil does not seem to preclude the use of the intravenous route for antiviral therapy.

Presented as a paper at the Joint European Research Meeting in Ophthalmology and Vision (JERMOV), 1995, Montpellier, France.

Key words: Acquired immune deficiency syndrome, Viral retinitis, Retinal detachment, Vitrectomy, Silicone oil, Scleral buckling.

\section{REFERENCES}

1. Freeman WR, Henderly DE, Wan WL, Causey D, Trousdale M, Green RL, Rao NA. Prevalence, pathophysiology, and treatment of rhegmatogenous retinal detachment in treated cytomegalovirus retinitis. Am J Ophthalmol 1987;103:527-36.

2. Jabs DA, Enger C, Haller J, de Bustros S. Retinal detachments in patients with cytomegalovirus retinitis. Arch Ophthalmol 1991;109:794-9.

3. Engstrom RE, Holland GN, Margolis TP, Muccioli C, Lindley JI, Belfort $\mathrm{R}$, et al. The progressive outer retinal necrosis syndrome. A variant of necrotizing herpetic retinopathy in patients with AIDS. Ophthalmology 1994;101:1488-502.
4. Dowler JGF, Towler HMA, Mitchell SM, Cooling RJ, Lightman SL. Retinal detachment and herpes virus retinitis in patients with AIDS. $\mathrm{Br} \mathrm{J}$ Ophthalmol 1995;79:575-80.

5. McCluskey P, Grigg J, Playfair TJ. Retinal detachments in patients with AIDS and CMV retinopathy: a role for laser photocoagulation. $\mathrm{Br} \mathrm{J}$ Ophthalmol 1995;79:153-6.

6. Irvine AR. Treatment of retinal detachment due to cytomegalovirus retinitis in patients with AIDS. Trans Am Ophthalmol Soc 1991;89:349-67.

7. Kupperman BD, Flores-Aguilar M, Quiceno JI, Capparelli EV, Levi L, Munguia D, Freeman WR. A masked prospective evaluation of outcome parameters for cytomegalovirus-related retinal detachment surgery in patients with acquired immune deficiency syndrome. Ophthalmology 1994;101:46-55.

8. Dugel PU, Liggett PE, Lee MB, Ziogas A, Forster DJ, Smith RE, Rao NA. Repair of retinal detachment caused by cytomegalovirus retinitis in patients with the acquired immunodeficiency syndrome. Am J Ophthalmol 1991;112:235-9.

9. Chuang EL, Davis JL. Management of retinal detachment associated with CMV retinitis in AIDS patients. Eye 1992;6:28-34.

10. Regillo CD, Vander JF, Duker JS, Fischer DH, Belmont JB, Kleiner R. Repair of retinitis-related retinal detachments with silicone oil in patients with acquired immunodeficiency syndrome. Am J Ophthalmol 1992;113:21-7.

11. Freeman WR, Quiceno JI, Crapotta JA, Listhaus A, Munguia D, Aguilar MF. Surgical repair of rhegmatogenous retinal detachment in immunosuppressed patients with cytomegalovirus retinitis. Ophthalmology 1992;99:466-74.

12. Lim JI, Enger C, Haller JA, Campochiaro PA, Meredith TA, de Bustros S, et al. Improved visual results after surgical repair of cytomegalovirus-related retinal detachments. Ophthalmology 1994;101:264-9.

13. Davis JL, Serfass MS, Lai MY, Trask DK, Azen SP. Silicone oil in repair of retinal detachments caused by necrotizing retinitis in HIV infection. Arch Ophthalmol 1995;113:1401-9.

14. Kao GW, Peyman GA, Fiscella R, House B. Retinal toxicity of ganciclovir in vitrectomy infusion solution. Retina 1987;7:80-3.

15. Sidikaro Y, Silver Y, Holland GN, Kreiger AE. Rhegmatogenous retinal detachments in patients with AIDS and necrotizing retinal infections. Ophthalmology 1991;98:129-35.

16. Freeman WR, Friedberg DN, Berry C, Quiceno JI, Behette M, Fullerton SC, Munguia D. Risk factors for development of rhegmatogenous retinal detachment in patients with cytomegalovirus retinitis. Am J Ophthalmol 1993;116:713-20.

17. Orellana J, Teich SA, Lieberman RM, Restrepo S, Peairs R. Treatment of retinal detachments in patients with the acquired immune deficiency syndrome. Ophthalmology 1991;98:939-43.

18. Garcia RF, Aguilar MF, Quiceno JI, Capparelli EV, Munguia D, Kuppermann BD, et al. Results of rhegmatogenous retinal detachment repair in cytomegalovirus retinitis with and without scleral buckling. Ophthalmology 1995;102:236-45.

19. Nasemann JE, Mutsch A, Wiltfang R, Klauss V. Early pars plana vitrectomy without buckling procedure in cytomegalovirus retinitis-induced retinal detachment. Retina 1995;15:111-6. 